\title{
Antiepileptic Drug Actions
}

\author{
Robert L. Macdonald \\ Department of Neurology, University of Michigan Medical Center, Ann Arbor, Michigan, U.S.A.
}

Summary: Antiepileptic drugs (AEDs) vary in their efficacy against generalized tonic-clonic, myoclonic, and absence seizures, suggesting different mechanisms of action. Phenytoin (PHT), carbamazepine (CBZ), and valproate (VPA) reduced the ability of mouse central neurons to sustain high-frequency repetitive firing of action potentials (SRF) at therapeutic free serum concentrations. Phenobarbital (PB) and the benzodiazepines (BZDs), diazepam (DZP), clonazepam (CZP), and lorazepam (LZP), also reduced SRF, but only at supratherapeutic free serum concentrations achieved in treatment of generalized tonicclonic status epilepticus. These AEDs interact with sodium channels to slow the rate of recovery of the channels from inactivation. The BZDs and PB enhanced $\gamma$-aminobutyric acid (GABA) responses evoked on mouse central neurons by binding to two different sites on the $\mathrm{GABA}_{\mathrm{A}}$ receptor channel. BZDs increased the frequency of GABA receptor channel openings. In contrast, barbiturates increased the open duration of these channels. VPA enhanced brain GABA concentration and may enhance release of GABA from nerve terminals. Ethosuximide (ESM) reduced a small transient calcium current which has been shown to be involved in slow rhythmic firing of certain neurons. Reduction of SRF, enhancement of GABA-ergic inhibition, and reduction of calcium current may be, in part, the bases for AED action against generalized tonic-clonic, myoclonic, and absence seizures, respectively. Key Words: Anticonvulsants-Neuropharmacology-Membrane potentials-Calcium.
Despite substantial interest in developing safer and more efficacious antiepileptic drugs (AEDs), six classes of AEDs, which have been in use for 15-75 years, continue to be the primary drugs used to treat patients with epilepsy. The AED classes are hydantoins [phenytoin (PHT)], iminostilbenes [carbamazepine (CBZ)], barbiturates [phenobarbital (PB), primidone (PRM)], fatty acids [valproate (VPA)], benzodiazepines (BZDs) [clonazepam (CZP), diazepam (DZP), nitrazepam (NZP), lorazepam (LZP)], and succinimides [ethosuximide (ESM)]. These AEDs are used to treat generalized tonic-clonic, myoclonic, absence, and partial seizures. Multiple classes of AED have been used because of variable selectivity against the epilepsies (Table 1). PHT and $\mathrm{CBZ}$ are administered exclusively for generalized tonic-clonic and partial seizures, whereas ESM is used exclusively against generalized absence seizures. VPA, barbiturates, and BZDs have a broader range of action, but drugs from the latter two classes have use

Address correspondence and reprint requests to Dr. R. L. Macdonald at the Neuroscience Laboratory Building, 1103 East Huron, Ann Arbor, Michigan 48104-1687, U.S.A. limited by sedation and development of tolerance. The different selectivity of the AEDs suggests multiple mechanisms of action.

Consistent with this view, several neuronal properties have been shown to be regulated by AEDs (Macdonald and McLean, 1986). AEDs reduce sustained, high-frequency, repetitive firing of action potentials (SRF), enhance GABAergic inhibition, and reduce calcium currents. In the sections below, these three mechanisms will be discussed.

\section{EFFECTS OF AEDs ON SRF}

AEDs have been shown to alter many membrane properties of neurons and axons (Esplin, 1957; Raines and Standaert, 1966; Hershkowitz and Raines, 1978; Macdonald and McLean, 1986). However, to be an AED mechanism of action, the membrane effects must be produced at CSF and plasma concentrations free of protein binding in ambulatory patients. A direct membrane effect produced only at toxic free-plasma levels is unlikely to be a relevant AED mechanism of action. PHT, CBZ, VPA, antiepileptic BZDs, PB, and PRM blocked SRF in verte- 
TABLE 1. Different effectiveness of AEDs against the epilepsies

\begin{tabular}{cccc}
\hline Drug & GTCS/PS & MCS & GAS \\
\hline PHT & ++ & - & - \\
CBZ & ++ & - & - \\
VPA & ++ & ++ & ++ \\
PB & + & + & - \\
CZP & + & ++ & + \\
ESM & - & - & ++ \\
\hline
\end{tabular}

$\mathrm{PHT}=$ phenytoin $\mathbf{C B Z}=$ carbamazepine $; \mathrm{VPA}=$ valproate $\mathrm{PB}$ = phenobarbital $;$ CZP = clonazepam; $E S M=$ ethosuximide; GTCS = generalized tonic-clonic seizures; PS = partial seizures; MCS = myoclonic seizures; GAS = generalized absence seizures.

$++=$ Efficacy against the seizure type at nontoxic serum concentrations.

$+=$ Efficacy against the seizure type at toxic concentrations.

$-=$ No efficacy.

brate cortical and spinal cord neurons in cell culture (McLean and Macdonald, 1983; Macdonald and McLean, 1986). However, only PHT, CBZ, and VPA reduced SRF (Fig. 1) at therapeutic free-serum concentrations (Table 2).

The AED-induced block of SRF has several important properties. First, the block is voltage-dependent. Reduction of SRF by AEDs can be reversed by
TABLE 2. Effects of clinically used AEDs on sodium channel function ${ }^{a}$

\begin{tabular}{lccc}
\hline Drug & gNa & CONC & $\mathbf{R}_{\mathbf{x}}$ \\
\hline PHT & ++ & $>0.5 \mu \mathrm{g} / \mathrm{ml}$ & $>1.0 \mu \mathrm{g} / \mathrm{ml}$ \\
CBZ & ++ & $>0.5 \mathrm{mg} / \mathrm{ml}$ & $>0.8 \mu \mathrm{gl} l$ \\
VPA & ++ & $>0.5 \mu \mathrm{g} / \mathrm{ml}$ & $>2.5 \mu \mathrm{gl} l$ \\
PB & + & $>50 \mu \mathrm{gl}$ & $>5.0 \mu \mathrm{ml} / \mathrm{ml}$ \\
CZP & + & $>50 \mathrm{ng} / \mathrm{ml}$ & $?$ \\
ESM & - & - & - \\
\hline
\end{tabular}

a Several AEDs reduced sustained, high-frequency, repetitive firing of action potentials by interacting with sodium conductance $(\mathrm{gNa})$. It is likely that this action was to enhance sodium-channel inactivation.

$++=$ Effect of AED on sodium-channel function ( $\mathrm{gNa}$ ) at therapeutic free-serum concentrations.

$+=$ Effect on sodium-channel function at toxic concentrations. $-=$ No effect.

CONC = concentrations above which the AEDs modify sodium-channel function.

$\mathbf{R}_{\mathbf{x}}=$ minimum therapeutic free-serum concentrations against generalized tonic-clonic and partial seizures.

Other drug abbreviations as in Table 1.

maintained membrane hyperpolarization and increased by maintained membrane depolarization. Second, the effect of the AEDs is use-dependent. Following membrane depolarization, most neurons fire a train of action potentials with varying degrees of
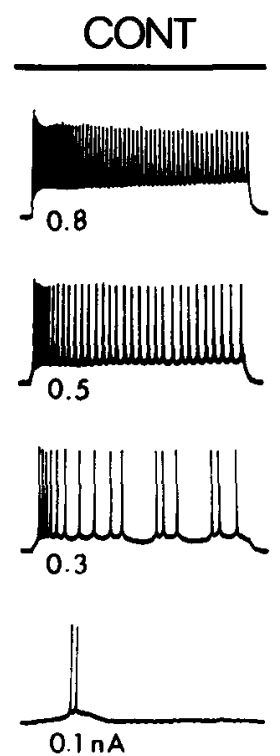

$E_{m}-65 m V$
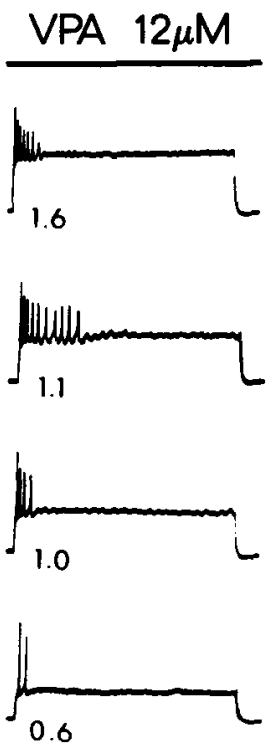

$-62 m V$
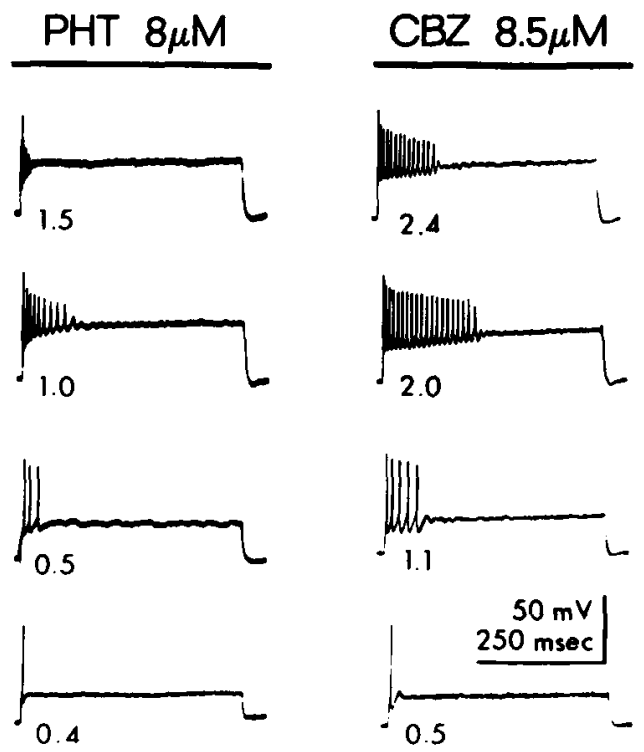

$-61 m V$

$-63 m v$

FIG. 1. Valproate (VPA), phenytoin (PHT), and carbamazepine (CBZ) limited sustained, high-frequency, repetitive firing of action potentials (SRF). Intracellular recordings were made from spinal cord neurons in cell culture, and increasing depolarizing-current pulses (EM) were applied. Magnitude of the current pulses is shown below each of the traces in nanoamps. The membrane potentials from which the depolarizing pulses were applied appear below each column. In control medium (CONT), SRF was obtained throughout all ranges of depolarization. In the presence of VPA, PHT, and CBZ, limitation of SRF was seen at each of the membrane potentials. (From McLean and Macdonald, 1983, 1986a,b.) 
spike frequency adaptation. However, in the presence of an AED, the action potentials within the train are progressively altered. The initial action potential is unaffected, but each subsequent one has a smaller amplitude and a lower rate of rise. Eventually, firing of action potentials fails during the depolarization. Third, the effect of the AEDs is time dependent. After SRF has been blocked, single evoked action potentials will have reduced the amplitude and the rate of rise for several hundred msec. Thus, removing the effect of the AED takes several hundred ms.

PHT and CBZ reduced the amplitude of sodiumdependent action potentials by increasing the voltage dependency of steady-state inactivation and by reducing the rate of recovery of sodium channels from inactivation (Courtney and Etter, 1983; McLean and Macdonald, 1983; Matsuki et al., 1984; Willow et al., 1985; McLean and Macdonald, 1986b). PHT, CBZ, $\mathrm{PB}$, and DZP all inhibited the binding of $\left[\mathrm{H}_{3}\right]-$ batrachotoxin A $20-\alpha$-benzoate (BTX-B) to sodium channels and reduced batrachotoxin-stimulated ${ }^{22} \mathrm{Na}$ influx in brain synaptic terminals (Willow et al., 1984). BTX-B is a toxin that binds to sodium channels at a site related to activation of sodium channel ion flux (Willow and Catterall, 1982).

The effects of the AEDs on sodium channels are similar to those of local anesthetic drugs (Strichartz, 1973; Courtney, 1975; Hille, 1977; Khodorov, 1981). The action of these drugs has been interpreted using the modulated-receptor hypothesis (Hille, 1977; Courtney and Etter, 1983). The sodium channel has been demonstrated to exist in three main conformations: a resting $(R)$ or activatable state, an open $(O)$ or conducting state, and an inactive (I) or nonactivatable state (Fig. 2). Under normal circumstances, when membrane potential is large and negative, most of the sodium channels are in the activatable state. Upon membrane depolarization, a large number of

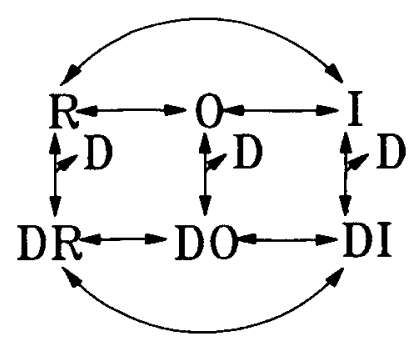

FIC. 2. Voltage-activated sodium channels have three main states: rest $(\mathrm{R})$, open $(\mathrm{O})$, or inactivated (1). The distribution of channels among these states in a given neuron is a function of membrane potential and time. When a local anesthetic or AED (D) binds to the channel (DR, DO, DI), the distribution of channels among states may change, and the transition rates between states may change. (See text for further discussion.) the sodium channels open, depending upon the level of the membrane depolarization. With progressive depolarization, some channels are converted to the inactive state; membrane depolarization now will open fewer channels. If the membrane is strongly depolarized, all channels may be in the inactive state, and no channels will open. To remove channel inactivation, the membrane must be hyperpolarized again to a large negative voltage.

The modulated-receptor hypothesis postulates that drugs bind to the different forms of these channels with different affinity. The AEDs likely bind to the inactive form of the channel (Fig. 2). Therefore, when a neuron has a large negative membrane potential, all the channels are closed and are not bound with high affinity by the AEDs. In contrast, when the cell is depolarized, a fraction of the channels are inactive, allowing equilibrium to shift toward the bound, inactive conformation of the channel. In such a model, AEDs can produce time-, voltage- , and use-dependent block of sodium-dependent action potentials because the fraction of inactive channels is increased by membrane depolarization and by repetitive firing. Since the drug that is bound to the inactive channels takes time to dissociate, the block is time dependent. Therefore, it is likely that AEDs block SRF of sodium action potentials by selectively binding to the inactive form of the sodium channel.

While the apparent mechanism of action of VPA is similar to that of PHT and CBZ (McLean and Macdonald, 1986a), VPA has not been shown to bind to the BTX-B binding site on sodium channels (Willow and Catterall, 1982) or to block batrachotoxin-stimulated ${ }^{22} \mathrm{Na}$ influx in brain synaptic terminals (Willow et al., 1984). Thus, VPA may bind to a different site on sodium channels than PHT and CBZ.

Barbiturates, PRM, and BZDs also block SRF, but only at supratherapeutic concentrations (Macdonald and McLean, 1986; McLean and Macdonald, 1988). However, barbiturates and BZDs block SRF at concentrations that are achieved in the treatment of generalized tonic-clonic status epilepticus (Table 2). Thus, it is likely that both PB and DZP block SRF at concentrations achieved in the treatment of generalized tonic-clonic status epilepticus and that this effect may contribute to their antiepileptic action in this clinical setting.

In contrast to PHT, CBZ, VPA, BZDs, PB, and PRM, the antiabsence drug ESM did not block SRF (Macdonald and McLean, 1986), reduce BTX-B binding (Willow and Catterall, 1982), or reduce batrachotoxin-stimulated ${ }^{22} \mathrm{Na}$ influx in brain synaptic terminals (Willow et al., 1984). Thus, blockade of SRF may be at least partly responsible for preventing 
GABA 2 UM

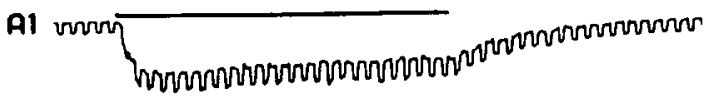

GABA 2 UM + DIAZEPAM $20 \mathrm{nM}$

ค2

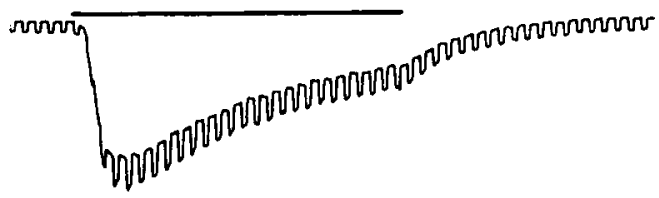

GABA 2 UM

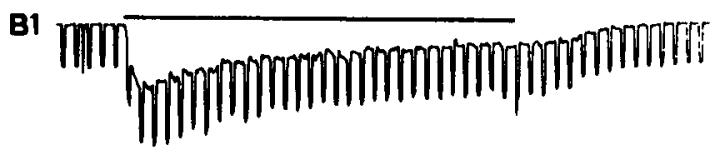

GABA 2 UM + PHENOBARBITAL 500 uM

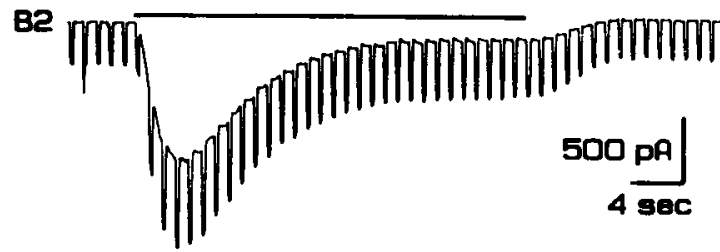

FIG. 3. GABA-receptor chloride currents were enhanced by diazepam (DZP) and phenobarbital (PB). Mouse spinal cord neurons were voltage clamped at $-75 \mathrm{mV}$ using the whole-cell recording technique. GABA (2 $\mu \mathrm{M})$ was applied by pressure ejection from blunt-tipped micropipettes positioned adjacent to the neuron. A: GABA-receptor current (A1) was enhanced when DZP (20 nM) was applied with GABA (A2). B: GABA-receptor current (B1) was also enhanced when applied to PB (500 $\mu M$ ) (B2). The equilibrium potential for chloride ions was 0 $\mathrm{mV}$; therefore, the GABA-receptor currents were inward (downgoing). (From Twyman et al., 1989.)

generalized tonic-clonic and partial seizures, but not generalized absence seizures.

\section{EFFECTS OF AEDS ON INHIBITORY MECHANISMS}

Synaptic inhibition is an important mechanism for regulation of central nervous system excitability. Enhancement of inhibition, therefore, would be an effective way to decrease abnormal excitability. Inhibition in the nervous system is mediated by a number of neurotransmitters and their corresponding receptors. Rapid inhibition is mediated primarily by amino acid neurotransmitters, including $\gamma$-aminobutyric acid (GABA) and glycine acting on postsynaptic GABA $\left(\mathrm{GABA}_{\mathrm{A}}\right)$ receptors and glycine receptors, respectively. Rapid forms of inhibition mediated by glycine and GABA receptors are produced by activation of neurotransmitter receptors where the proteins forming the receptor also form the channel (Grenningloh et al., 1987; Schofield et al., 1987).

The only form of inhibition clearly shown to be regulated by AEDs is GABAergic inhibition. Both barbiturates and BZDs enhance postsynaptic GABAreceptor current (Fig. 3). The GABA receptor has been shown to be an oligomeric complex consisting of at least two binding sites for GABA, allosteric regulatory binding sites for BZDs and $\beta$-carbolines, picrotoxin-like convulsant drugs and barbiturates, and a chloride channel (Polc et al., 1982; Tallman and Gallager, 1985; Olsen and Venter, 1986). The receptor appears to be formed from two peptide subunits, an $\alpha$-chain and a $\beta$-chain, with a stoiciometry of $\alpha_{2} \beta_{2}$ (Schofield et al., 1987), and there are at least three different isoforms of $\alpha$-chain (Levitan et al., 1988). The GABA binding site is on the $\beta$-chain, and the BZD binding site is on the $\alpha$-chain. Each peptide chain spans the membrane at least four times, having four membrane or $M$ regions. The juxtaposition of the $M$ regions is thought to form the chloride ion channel opened by GABA binding. A series of positive charges around the extracellular portion of the $M$ regions are presumably involved in regulating the negatively charged chloride ion entry and repelling the positively charged cations.

TABLE 3. Variable effects of AEDs on GABAergic inhibition

\begin{tabular}{cccc}
\hline Drug & GABA & CONC & $\mathbf{R}_{\mathrm{x}}$ \\
\hline PHT & - & - & - \\
CBZ & - & - & - \\
VPA & $+/ ?$ & $>50.0 \mu \mathrm{g} / \mathrm{ml}$ & $>2.5 \mu \mathrm{g} / \mathrm{ml}$ \\
PB & + & $>5.0 \mu \mathrm{gl}$ & $>5.0 \mu \mathrm{g} / \mathrm{ml}$ \\
CZP & ++ & $>1.0 \mathrm{ng} / \mathrm{ml}$ & $>2.6 \mathrm{ng} / \mathrm{ml}$ \\
ESM & - & - & - \\
\hline
\end{tabular}

$+/ ?=$ Questionable enhancement of GABA-receptor current due to enhanced release of GABA from presynaptic terminals.

$+=$ Weak enhancement of postsynaptic GABA current at high therapeutic and slightly toxic serum concentrations.

$++=$ Potent enhancement of postsynaptic GABA-receptor current at therapeutic free-serum concentrations. sion.

CONC $=$ Minimal effective concentrations to enhance GABAergic synaptic transmission.

$\mathbf{R}_{\mathrm{x}}=$ Threshold free-serum therapeutic concentrations against myoclonic seizures.

Drug abbreviations as shown in Table 1. 
Barbiturates and BZDs bind to specific allosteric regulatory binding sites on the GABA receptor. BZDs have been shown to enhance the binding of GABA to its receptor (Meiners and Salama, 1982; Skerritt et al., 1982) and to enhance GABA-receptor current (Choi et al., 1977; Macdonald and Barker, 1978). Phenobarbital, however, does not enhance the binding of GABA to its receptor (Olsen and Snowman, 1982) but does enhance GABA-receptor current (Macdonald and Barker, 1978). The BZDs DZP, CZP, and NZP all enhance GABA-receptor current at low nanomolar concentrations that are achieved in CSF and plasma unbound to plasma proteins (Skerritt and Macdonald, 1984) (Table 3). Similarly, PB enhances GABA-receptor current at a concentration achieved in ambulatory patients in CSF and plasma unbound to plasma proteins (Schulz and Macdonald, 1981) (Table 3).

While both BZDs and barbiturates enhance GABA-receptor current, they do so by different mechanisms (Study and Barker, 1981; Twyman et al., 1989). When GABA binds to its receptor and gates open the chloride ion channel, the channel opens and closes rapidly, forming bursts of openings interrupted by brief closures (Hamill et al., 1983; Macdonald et al., 1989). This bursting behavior of GABA-receptor currents appears to be a general property of neurotransmitter-gated receptor channels (Colquhoun and Sakmann, 1985). BZDs increase the frequency of occurrence of these bursting GABA-receptor currents (Bormann, 1988; Twyman et al., 1988 , 1989). Barbiturates, however, do not, but instead, appear to modify the stability of individual openings (Twyman et al., 1988, 1989). The GABAreceptor bursts are still present, but the openings within the bursts are prolonged, and there is more current flow per burst (Fig. 4). Thus, BZDs and barbiturates enhance GABA-receptor currents by binding to different sites and by regulating different properties of the GABA-receptor channel (Fig. 5).

In addition to enhancing postsynaptic GABA-receptor-channel properties, drugs that intensify the release of GABA are thought also to have antiepileptic properties. The most notable such drug is VPA. VPA has been demonstrated to block GABA catabolism by inhibiting succinic simialdehyde dehydrogenase (Chapman et al., 1982) and by increasing brain GABA levels, possibly selectively, in synaptic termi-

\section{CONTROL}

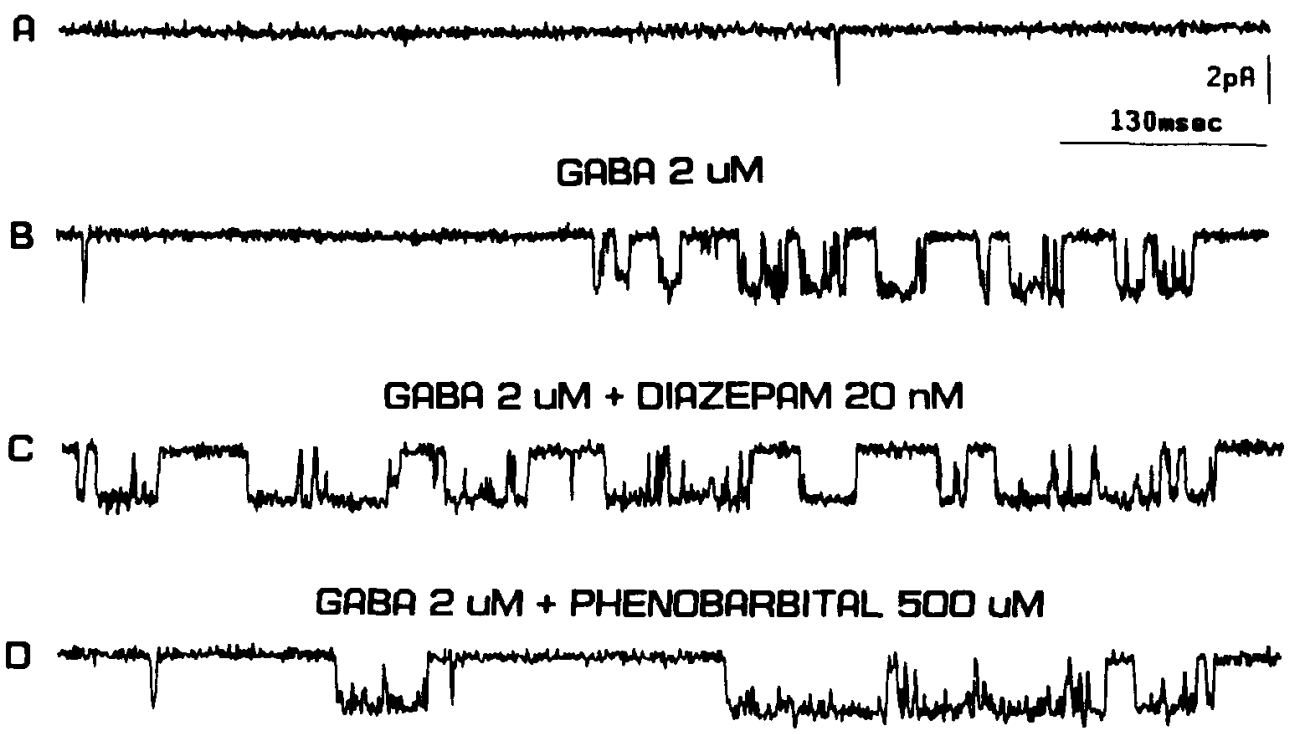

FIG. 4. Single-channel GABA-receptor currents were enhanced by diazepam (DZP) and phenobarbital (PB). Patches of mouse spinal cord neurons were removed using the "outside-out" configuration for patch-clamp recording. GABA was applied to the excised patches by locel pressure ejection. A: Prior to application of GABA, only rare, brief, spontaneous currents were recorded. Channel opening produced a downward deflection of the current recording. B: Following application of GABA (2 $\mu M)$, single-channel currents increased in frequency and occurred as single individual openings or in bursts of openings. C: In the presence of DZP (20 nM), GABA evoked increased single-channel activity. D: In the presence of PB $(500 \mu M)$, GABA again increased GABA-receptor channel activity. Membrane patches were voltage clamped at $-75 \mathrm{mV}$, and chloride equilibrium potential was $0 \mathrm{mV}$. DZP increased the frequency of channel opening without altering the basic duration of openings, whereas PB did not increase the frequency of channel openings but prolonged individual openings. (From Twyman et al., 1989.) 


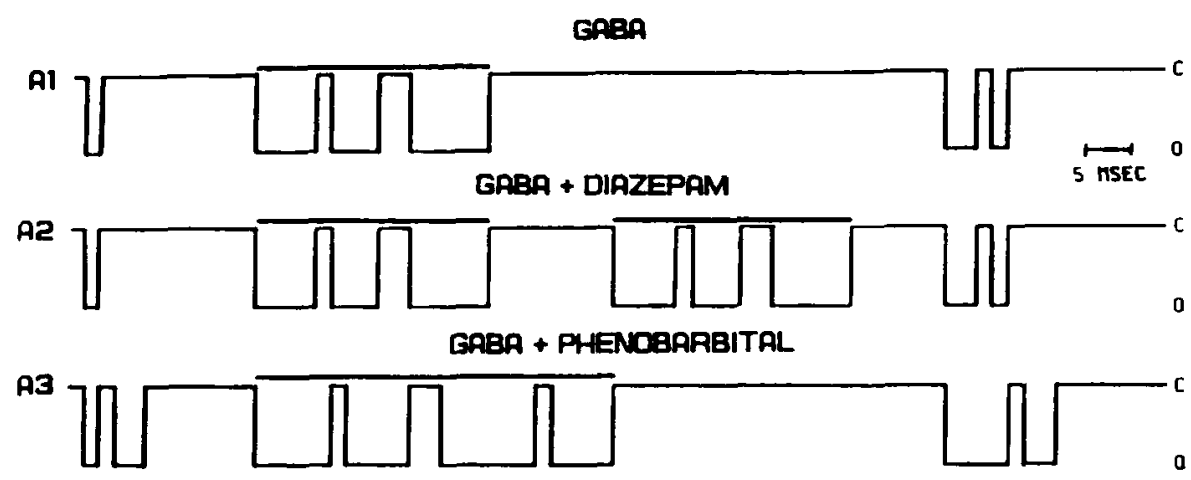

$\mathbf{8}$

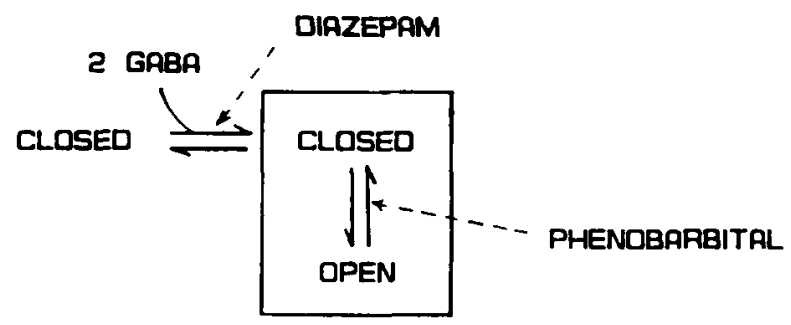

BURST

FIG. 5. Barbiturates and benzodiazepines had different sites of action to enhance GABA-receptor current. A: GABA (A1) involved frequent channel openings in isolation or in bursts. Prolonged bursts are overscored. In the presence of diazepam (DZP) (A2), bursts with stable long openings were of the same duration but more frequent. This resulted in more GABA-receptor current. In the presence of phenobarbital (PB) (A3), bursts were prolonged and consisted of longer single-channel openings. B: In a simplified burst kinetic model for the GABA-receptor-channel complex, 2 molecules of GABA bind to the receptor to gate open the chloride channel into bursts. DZP enhanced GABA binding affinity to increased burst frequency without altering individual GABA-receptor bursts. PB altered the GABA-receptor bursts by prolonging the time spent in the open state. This site of action may be at or near the channel to modify the properties of channel gating. (From Twyman et al., 1989.)

nal pools (Larsson et al., 1986). While still unproven (Chapman et al., 1982), it has been proposed that the increased brain GABA levels result in increased GABA release (Gram et al., 1988) and, therefore, an antiepileptic action.

\section{EFFECTS OF AEDS ON CALCIUM CURRENTS}

In addition to effects on sodium channels, clinically used AEDs have demonstrated effects on calcium channels (Macdonald and McLean, 1986). Calcium enters neurons through three different voltage-dependent calcium channels (Nowycky, et al., 1985), designated $\mathrm{L}, \mathrm{N}$, and $\mathrm{T}$ (Fig. 6). These calcium channels differ in their voltage dependency for activation and inactivation, rate of inactivation, and individual channel conductance. In addition, they have a different agonist and antagonist pharmacology. L-channel conductance is large, and L-current is long-lasting and slowly inactivating. T-channel conductance is small, and T-currents are transient and inactivate rapidly. $\mathrm{N}$-channel conductance is intermediate in magnitude, and $\mathrm{N}$-current inactivates at a rate between that of the $T$ - and $L$-currents.

PHT, barbiturates, and BZDs have been demonstrated to reduce calcium influx into synaptic terminals (Blaustein and Ector, 1975; Ondrusek et al., 1979; Leslie et al., 1980; Ferrendelli and DanielsMcQueen, 1982) and to block presynaptic release of neurotransmitter (Somjen, 1963; Kalant and Grose, 1967; Richter and Waller, 1977; Yarri et al., 1977; Mitchell and Martin, 1978) at supratherapeutic concentrations. The barbiturates PB and pentobarbital block both $\mathrm{L}$ - and $\mathrm{N}$-currents, without affecting $\mathrm{T}$ calcium current, at anesthetic but not free-serum AED concentrations (Gross and Macdonald, 1987, 1988) (Fig. 6). Similarly, PHT (McLean and Macdonald, 1983) and DZP (Skerritt et al., 1984) have been demonstrated to block calcium currents at supratherapeutic AED concentrations.

In contrast, ESM and the trimethadione metabo- 
lite, dimethadione, have recently been shown to affect $\mathrm{T}$-calcium currents in thalamic neurons (Coulter et al., 1988) and in primary afferent neurons (Gross et al., 1989) at therapeutically relevant concentrations (Fig. 7) (Table 4). It has been proposed that T-calcium currents are important pacemaker currents in thalamic neurons and that these currents may be responsible, in part, for the $3-\mathrm{Hz}$ rhythm seen in the electroencephalogram of patients with generalized absence seizures (Coulter et al., 1988). Blockade of T-calcium currents by ESM or trimethadione, then, would disrupt the slow rhythmic firing of thalamic neurons as well as the spike and wave discharge. However, VPA and CZP did not alter T-calcium cur- rents in primary afferent neurons (Gross et al., 1989). Thus, it is possible that this effect on T-calcium currents may underlie the effect of ESM and trimethadione on generalized absence seizures but not the effect of VPA and the BZDs.

\section{SUMMARY}

AEDs can be divided mechanistically into at least three classes (Table 5) based on ability to block SRF by enhancing sodium-channel inactivation, to enhance GABAergic inhibition, and to block slow, pacemaker-driven, repetitive firing by blocking T-calcium current. AEDs such as PHT and CBZ limit SRF

\section{Pentobarbital $500 \mu \mathrm{M}$}
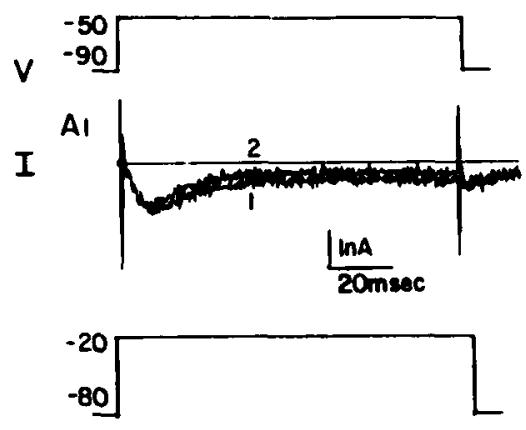

B।
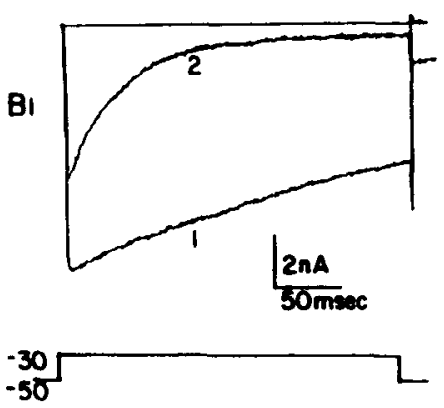

Cl

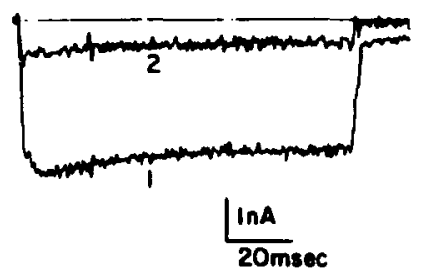

\section{Phenobarbital $2 \mathrm{mM}$}

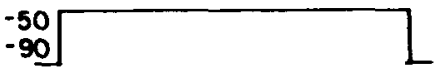

A2
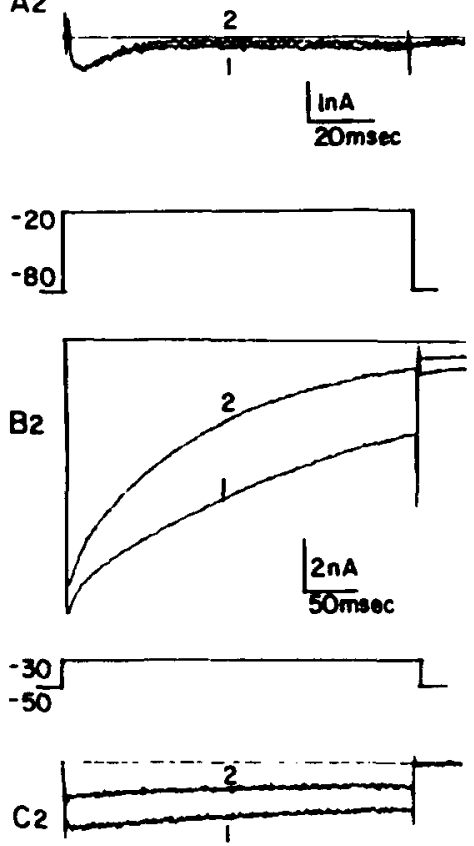

$3 n A$

\section{Nifedipine}

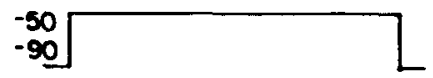

A3
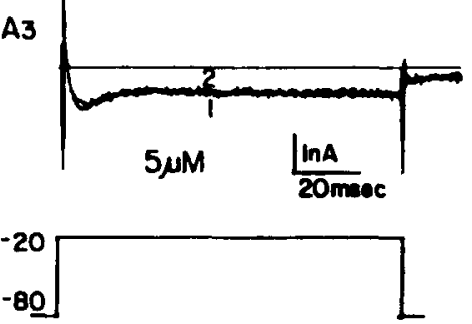

$\mathbf{B 3}$
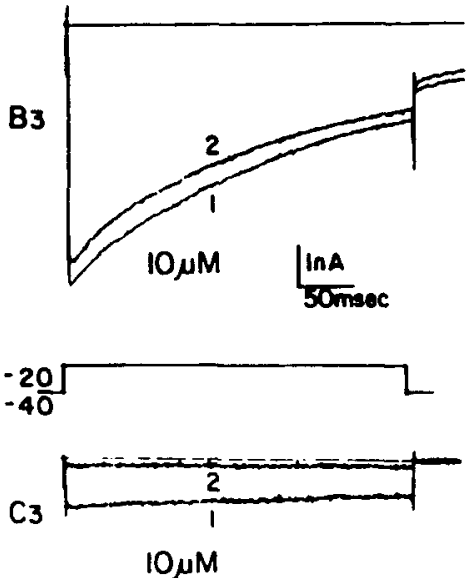

$2 n A$

$50 \mathrm{msec}$

FIG. 6. Pentobarbital and phenobarbital (PB) reduced $\mathrm{N}$ - and $\mathrm{L}$ - but not T-calcium currents, whereas nifedipine selectively reduced L-calcium current. T- , L- , and N/L-currents were evoked using different membrane-holding potentials and depolarizing commands. A control current was obtained (1) and the effects of pentobarbital $\left(A_{1}, B_{1}, C_{1}\right), P B\left(A_{2}, B_{2}, C_{2}\right)$, and nifedipine $\left(A_{3}, B_{3}, C_{3}\right)$ were determined by applying the drugs locally to the neuron from a glass micropipette. The current was then evoked again (2) and superimposed on the control current. A: None of the drugs altered T-calcium current. B: Pentobarbital and PB, but not nifedipine, increased the rate of inactivation of primarily the N-component of the N/L-calcium current. C: Pentobarbital, PB, and nifedipine decreased L-calcium current. Recordings were made from mouse dorsal root ganglion neurons grown in cell culture. (From Gross and Macdonald, 1987.) 
CONTROL

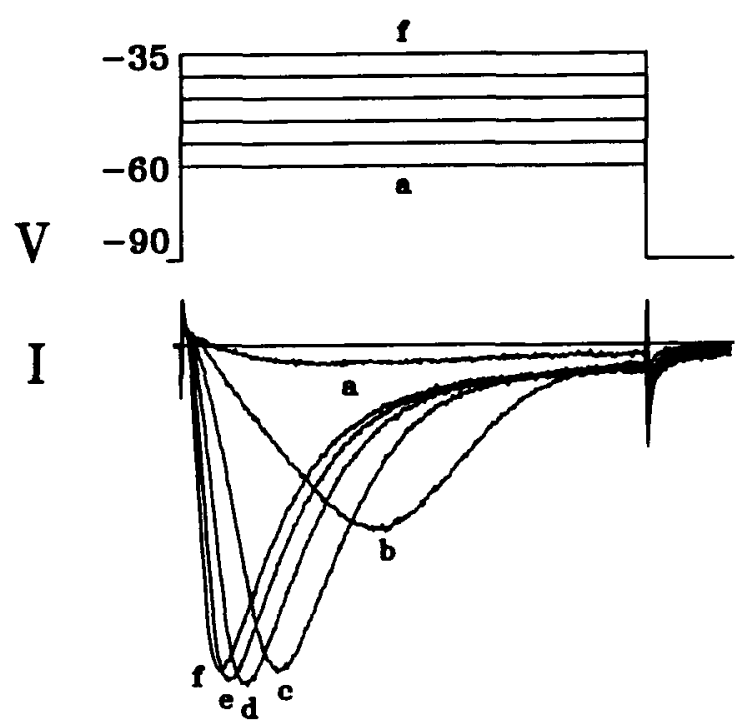

ETHOSUXIMIDE $1 \mathrm{mM}$
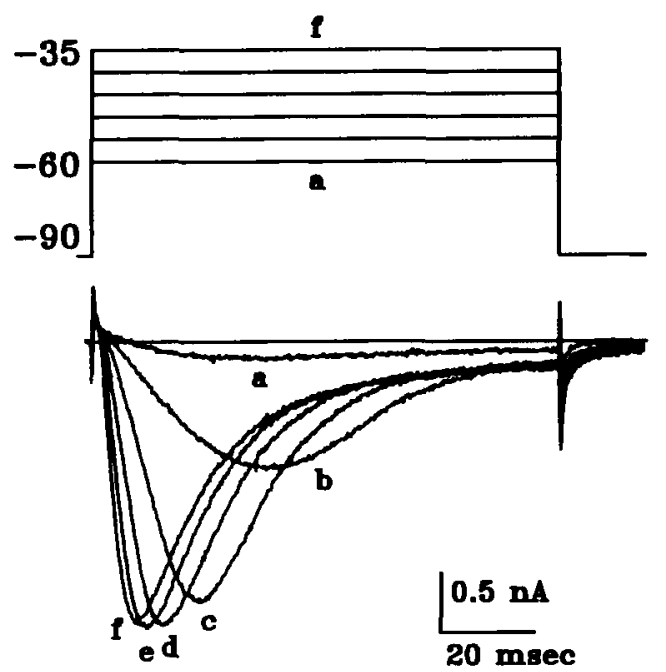

FIG. 7. Ethosuximide (ESM) reduced T-calcium current. Voltage-clamp recordings were obtained from acutely dissociated rat nodose ganglion neurons using the whole-cell recording technique. The neurons were held at $-90 \mathrm{mV}$, and depolarizing commands in $5 \mathrm{mV}$ increments were applied from -60 to $-35 \mathrm{mV}$. Under control conditions, this voltage-clamp sequence evoked a series of T-calcium currents. In the presence of ESM, currents at each command were reduced in amplitude. (From Gross and Macdonald, unpublished.)

but do not modify GABAergic synaptic transmission or T-calcium current (Type I AEDs). Drugs such as PB, VPA, and the BZDs have dual actions, enhancing GABAergic synaptic transmission and blocking SRF; however, they do not alter T-calcium current (Type II AEDs). ESM and dimethadione, on the other hand, have no effect on either postsynaptic GABA responses or SRF, but they block T-calcium currents (Type III AEDs).

These results further suggest that the ability of a Type I AED to block generalized tonic-clonic seizures and some forms of partial seizures may correlate with the ability of the AED to block SRF. On the other

TABLE 4. Efficacy against T-calcium currents

\begin{tabular}{lccc}
\hline Drug & gCaT & CONC & $\mathbf{R}_{\mathbf{x}}$ \\
\hline PHT & - & - & - \\
CBZ & $?$ & - & - \\
VPA & - & - & - \\
PB & - & - & - \\
CZP & - & - & - \\
ESM & + & $>150 \mu \mathrm{g} / \mathrm{ml}$ & $>40 \mu \mathrm{g} / \mathrm{ml}$ \\
\hline
\end{tabular}

$\mathrm{gCaT}=\mathrm{T}$-calcium current conductance.

CONC $=$ concentrations above which the AEDs modify sodium-channel function.

$\mathbf{R}_{\mathrm{x}}=$ Threshold free-serum therapeutic concentration of ESM, which was effective against generalized absence seizures.

$+=$ Effective at slightly supratherapeutic concentrations (CONC).

Drug abbreviations as in Table 1. hand, the ability of a Type II AED to enhance GABAergic synaptic transmission may be one mechanism to block myoclonic seizures. Whether or not generalized absence seizures are blocked by enhancement of GABAergic inhibition is uncertain, but the possibility remains. Type III AEDs may be effective against generalized absence seizures in humans owing to their effect on T-calcium current. This mechanistic classification of AEDs must remain tentative at the present time, since the actions described have not been directly demonstrated to be antiepileptic in experimental animals. Nonetheless, it is likely that cellular mechanisms such as those demonstrated in vitro

TABLE 5. Efficacy of AEDs against sodium channels

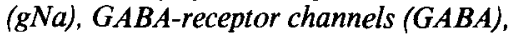
and T-calcium channels ( $\mathrm{gCaT}$ )

\begin{tabular}{lccc}
\hline Drug & gNa & GABA & gCaT \\
\hline PHT & ++ & - & - \\
CBZ & ++ & - & $?$ \\
VPA & ++ & $+/ ?$ & - \\
PB & + & + & - \\
CZP & + & ++ & - \\
ESM & - & - & + \\
\hline
\end{tabular}

$\mathrm{gCaT}=\mathrm{T}$-calcium current conductance.

$\mathrm{gNa}=$ sodium conductance.

Efficacy patterns may correlate with drug actions against generalized tonic-clonic and partial seizures, myoclonic seizures, and generalized absence seizures.

Drug abbreviations as in Table 1. 
are important for antiepileptic efficacy. Further investigation may lead to a classification of AEDs based on mechanistic rather than empirical bases.

\section{REFERENCES}

Blaustein MP, Ector AC. Barbiturate inhibition of calcium uptake by depolarized nerve terminals in vitro. Mol Pharmacol 1975;11:369-78.

Bormann J. Electrophysiology of GABA and $\mathrm{GABA}_{\mathrm{B}}$ receptor subtypes. TINS 1988;11:112-6.

Chapman A, Keane PI, Meldrum BS, Simiand J, Vernieres JC Mechanism of anticonvulsant action of valproate. Prog Neurobiol 1982;19:315-59.

Choi DW, Farb DH, Fischbach GD. Chlordiazepoxide selectively augments GABA action in spinal cord cell cultures. Nature (Lond) 1977;269:342-4.

Colquhoun D, Sakmann B. Fast events in single-channel currents activated by acetylcholine and its analogues at the frog muscle endplate. J Physiol (Lond) 1985;369:501-57.

Coulter DA, Hugenard JR, Prince DA. Anticonvulsants depress calcium spikes and calcium currents of mammalian thalamic neurons in vitro. Soc Neurosci Abstr 1988;14:262.

Courtney KR. Mechanism of frequency-dependent inhibition of sodium currents in myelinated nerve by the lidocaine derivative GEA 968. $J$ Pharmacol Exp Ther 1975;195:225-36.

Courtney KR, Etter EF. Modulated anticonvulsant block of sodium channels in nerve and muscle. Eur $J$ Pharmacol 1983;88:1-9.

Esplin D. Effect of diphenylhydantoin on synaptic transmission in the cat spinal cord and stellate ganglion. J Pharmacol Exp Ther 1957; 120:301-23.

Ferrendelli JA, Daniels-McQueen S. Comparative actions of phenytoin and other anticonvulsant drugs on potassium- and veratridine-stimulated calcium uptake in synaptosomes. $J$ Pharmacol Exp Ther 1982;220:29-34.

Gram L, Larsson OM, Johnson AH, Schousboe A. Effects of valproate, vigabatrin and aminooxyacetic acid on release of endogenous and exogenous GABA from cultured neurons. Epilepsy Res 1988;2:87-95.

Grenningloh G, Rienitz A, Schmitt B, et al. The strychnine-binding subunit of the glycine receptor shows homology with nicotinic acetylcholine receptors. Nature 1987;328:215-20.

Gross RA, Kelly KM, Macdonald RL. Ethosuximide and dimethadione selectively reduce calcium currents in cultured sensory neurons by different mechanisms. Neurology 1989;39:412.

Gross RA, Macdonald RL. Barbiturates and nifedipine have different and selective effects on calcium currents of mouse DRG neurons in culture: a possible basis for differing clinical actions. Neurology 1987;18:443-51.

Gross RA, Macdonald RL. Differential actions of pentobarbitone on calcium current components of mouse sensory neurones in culture. J Physiol (Lond) 1988;405:187-203.

Hamill OP, Bormann J, Sakmann B. Activation of multiple conductance state chloride channels in spinal neurones by glycine and GABA. Nature 1983;305:805-8.

Hershkowitz N, Raines A. Effects of carbamazepine on muscle spindle discharges. J Pharmacol Exp Ther 1978;204:581-91.

Hille B. Hydrophilic and hydrophobic pathways for the drug-receptor reaction. J Gen Physiol 1977;69:497-515.

Kalant H, Grose W. Effects of ethanol and pentobarbital on release of acetylcholine from cerebral cortex slices. $J$ Pharmacol Exp Ther 1967;158:386-93.

Khodorov BI. Sodium inactivation and drug-induced immobilization of the gating charge in nerve membrane. Prog Biophys $\mathrm{Mol}$ Biol 1981:37:49-89.

Larsson OM, Gram L, Schousboe L, Schousboe A. Differential effect of gamma-vinyl GABA and valproate on GABA-transaminase from cultured neurons and astrocytes. Neuropharmacology 1986;25:617-25.
Lesiie SW, Friedman MB, Coleman RR. Effects of chlordiazepoxide on depolarization-induced calcium influx into synaptosomes. Biochem Pharmacol 1980;29:2439-43.

Levitan ES, Schofield PR, Burt DR et al. Structural and functional basis for $\mathrm{GABA}_{\mathrm{A}}$ receptor heterogeneity. Nature 1988; 335:76-9.

Macdonald RL, Barker JL. Benzodiazepines specifically modulate GABA-mediated postsynaptic inhibition in cultured mammalian neurones. Nature 1978;271:563-4.

Macdonald RL, McLean MJ. Anticonvulsant drugs: mechanisms of action. In: Delgado-Escueta AV, Ward AA Jr, Woodbury DM, Porter RJ, eds. Antiepileptic drugs: mechanisms of action (Advances in Neurology, Vol. 44). New York: Raven Press, 1986:713-36

Macdonald RL, Rogers CJ, Twyman RE. Kinetic properties of chloride channels gated by $\gamma$-aminobutyric acid in mouse spinal cord neurones in cell culture. J Physiol (Lond) 1989; 410:479-99.

McLean MJ, Macdonald RL. Multiple actions of phenytoin on mouse spinal cord neurons in cell culture. $J$ Pharmacol Exp Ther 1983;227:779-89.

McLean MJ, Macdonald RL. Sodium valproate, but not ethosuximide, produces use- and voltage-dependent limitation of high frequency repetitive firing of action potentials of mouse central neurons in cell culture. $J$ Pharmacol Exp Ther 1986a; 237:1001-11.

McLean MJ, Macdonald RL. Carbamazepine and 10,11-epoxycarbamazepine produce use- and voltage-dependent limitation of rapidly firing action potentials of mouse central neurons in cell culture. J Pharmacol Exp Ther 1986b;238:727-38.

McLean MJ, Macdonald RL. Benzodiazepines, but not beta carbolines, limit high frequency repetitive firing of action potentials of spinal cord neurons in cell culture. J Pharmacol Exp Ther 1988;244:789-95.

Meiners BA, Salama AI. Enhancement of benzodiazepine and GABA binding by the novel anxiolytic, tracazolate. Eur J Pharmacol 1982;78:315-22.

Mitchell PR, Martin IL. The effects of benzodiazepines on K+ stimulated release of GABA. Neuropharmacology 1978; 17:317-20.

Nowycky MC, Fox AP, Tsien RW. Three types of neural calcium channels with different calcium agonist sensitivity. Nature $1985 ; 316: 440-3$.

Olsen RW, Snowman AM. Chloride-dependent enhancement by barbiturates of $\gamma$-aminobutyric acid receptor binding. $J$ Neurosci 1982;2:1812-23.

Olsen RW, Venter JC, eds. Benzodiazepine/GABA receptors and chloride channels: Structure and functional properties (Receptor Biochemistry and Methodology, vol. 5). New York: Alan R. Liss, 1986.

Ondrusek MG, Belknap JK, Leslie SW. Effects of acute and chronic barbiturate administration on synaptosomal calcium accumulation. Mol Pharmacol 1979;1 5:386-95.

Polc P, Bonetti EP, Schaffner R, Haefely W. A three-state model of the benzodiazepine receptor explains the interactions between the benzodiazepine antagonist Ro 15-1788, benzodiazepine tranquilizers, $\beta$-carbolines, and phenobarbitone. Naunyn Schmiedebergs Arch Pharmacol 1982;321:260-4.

Raines A, Standaert FG. Pre- and post-junctional effects of DPH at the cat soleus neuromuscular junction. J Pharmacol Exp Ther 1966; 153:361-6.

Richter JA, Waller MB. Effects of pentobarbital on the regulation of acetylcholine content and release in different regions of rat brain. Biochem Pharmacol 1977;26:609-15.

Schofield PR, Darlison MG, Fujita $\mathrm{N}$ et al. Sequence and functional expression of the GABA receptor shows a ligand-gated receptor super-family. Nature 1987;328:221-7.

Schulz DW, Macdonald RL. Barbiturate enhancement of GABAmediated inhibition and activation of chloride ion conductance: correlation with anticonvulsant and anesthetic actions. Brain Res 1981;209:177-88. 
Skerrit JH, Macdonald RL. Benzodiazepine receptor ligand actions on GABA responses. Benzodiazepines, CL 218872, zopiclone. Eur J Pharmacol 1984;101:127-34.

Skerrit JH, Werz MA, McLean MJ, Macdonald RL. Diazepam and its anomalous p-chloro-derivative Ro 5-4864: comparative effects on mouse neurons in cell culture. Brain Res 1984; 310:99-105.

Skerritt JH, Willow M, Johnson GAR. Diazepam enhancement of low affinity GABA binding to rat brain membranes. Neurosci Lett 1982;29:63-6.

Somjen GG. Effects of ether and thiopental on spinal presynaptic terminals. J Pharmacol Exp Ther 1963;140:393-402.

Strichartz GR. The inhibition of sodium currents in myelinated nerve by quaternary derivatives of lidocaine. $J$ Gen Physiol 1973;62:37-57.

Study RE, Barker JL. Diazepam and $(+/-)$ pentobarbital: fluctuation analysis reveals different mechanisms for potentiation of $\gamma$-aminobutyric acid responses in cultured central neurons Proc Natl Acad Sci USA 1981;78:7180-4.

Tallman J, Gallager D. The GABA-ergic system: a locus of benzodiazepine action. Annu Rev Neurosci 1985;8:21-44.
Twyman RE, Rogers CJ, Macdonald RL. Differential mechanisms for enhancement of GABA by diazepam and phenobarbital: a single channel study. Neurology 1988;38:121.

Twyman RE, Rogers CJ, Macdonald RL. Differential regulation of $\mathrm{GABA}_{\mathrm{A}}$ receptor channels by diazepam and phenobarbital. $A n n$ Neurol 1989:25:213-20.

Willow M, Catterall WA. Inhibition of binding of $\left[{ }^{3} \mathrm{H}\right]$ Batrachotoxin A 20- $\alpha$-benzoate to sodium channels by the anticonvulsant drugs diphenylhydantoin and carbamazepine. $M o l$ Pharmacol 1982;22:627-35.

Willow M, Gonoi T, Catterall WA. Voltage clamp analysis of the inhibitory actions of diphenylhydantoin and carbamazepine on voltage-sensitive sodium channels in neuroblastoma cells. $\mathrm{Mol}$ Pharmacol 1985;27:549-58.

Willow M, Kuenzel EA, Catterall WA. Inhibition of voltage-sensitive sodium channels in neuroblastoma cells and synaptosomes by the anticonvulsant drugs diphenylhydantoin and carbamazepine. Mol Pharmacol 1984;25:228-34.

Yaari Y, Pincus JH, Argov Z. Depression of synaptic transmission by diphenylhydantoin. Ann Neurol 1977;1:334-8. 